\title{
An Improved Estimator For Black-Scholes-Merton Implied Volatility
}

\author{
WinfRIED G. HALLERBACH
}

\begin{tabular}{|l|l|}
\hline \multicolumn{2}{|l|}{ ERIM REPORT SERIES RESEARCH IN MANAGEMENT } \\
\hline ERIM Report Series reference number & ERS-2004-054-F\&A \\
\hline Publication & July 2004 \\
\hline Number of pages & 17 \\
\hline Email address corresponding author & hallerbach@few.eur.nl \\
\hline Address & Erasmus Research Institute of Management (ERIM) \\
& Rotterdam School of Management / Rotterdam School of \\
& Economics \\
& Erasmus Universiteit Rotterdam \\
& P.O. Box 1738 \\
& 3000 DR Rotterdam, The Netherlands \\
& Phone: $\quad+31104081182$ \\
& Fax: $\quad+31104089640$ \\
& Email: info@erim.eur.nl \\
& Internet: $\quad$ www.erim.eur.nl \\
\hline
\end{tabular}

Bibliographic data and classifications of all the ERIM reports are also available on the ERIM website: www.erim.eur.nl 


\title{
ERASMUS RESEARCH INSTITUTE OF MANAGEMENT
}

\author{
REPORT SERIES \\ RESEARCH IN MANAGEMENT
}

\begin{tabular}{|c|c|c|}
\hline \multicolumn{3}{|c|}{ BIBLIOGRAPHIC DATA AND CLASSIFICATIONS } \\
\hline Abstract & \multicolumn{2}{|c|}{$\begin{array}{l}\text { We derive an estimator for Black-Scholes-Merton implied volatility that, when compared to the } \\
\text { familiar Corrado \& Miller [JBaF, 1996] estimator, has substantially higher approximation } \\
\text { accuracy and extends over a wider region of moneyness. }\end{array}$} \\
\hline \multirow{3}{*}{$\begin{array}{l}\text { Library of Congress } \\
\text { Classification } \\
\text { (LCC) }\end{array}$} & 5001-6182 & Business \\
\hline & $4001-4280.7$ & Finance Management, Business Finance, Corporation Finance \\
\hline & HG 6024+ & Options \\
\hline \multirow{5}{*}{$\begin{array}{l}\text { Journal of Economic } \\
\text { Literature } \\
\text { (JEL) }\end{array}$} & M & Business Administration and Business Economics \\
\hline & G 3 & Corporate Finance and Governance \\
\hline & $\mathrm{C} 13$ & Estimation \\
\hline & $\mathrm{C} 63$ & Computational techniques \\
\hline & $\mathrm{G} 13$ & Futures pricing \\
\hline \multirow{3}{*}{$\begin{array}{l}\text { European Business Schools } \\
\text { Library Group } \\
\text { (EBSLG) }\end{array}$} & $85 \mathrm{~A}$ & Business General \\
\hline & $220 \mathrm{~A}$ & Financial Management \\
\hline & $220 \mathrm{R}$ & Option markets \\
\hline \multicolumn{3}{|c|}{ Gemeenschappelijke Onderwerpsontsluiting (GOO) } \\
\hline \multirow[t]{3}{*}{ Classification GOO } & 85.00 & Bedrijfskunde, Organisatiekunde: algemeen \\
\hline & 85.30 & Financieel management, financiering \\
\hline & 85.33 & Beleggingsleer \\
\hline \multirow[t]{3}{*}{ Keywords GOO } & \multicolumn{2}{|c|}{ Bedrijfskunde / Bedrijfseconomie } \\
\hline & \multicolumn{2}{|c|}{ Financieel management, bedrijfsinanciering, besliskunde } \\
\hline & \multicolumn{2}{|c|}{ Optiehandel, omloopsnelheid } \\
\hline Free keywords & \multicolumn{2}{|c|}{ Implied volatility, options, approximation methods } \\
\hline
\end{tabular}




\title{
An Improved Estimator For Black-Scholes-Merton Implied Volatility
}

\author{
Winfried G. Hallerbach *) \\ this version: July 5, 2004 \\ Erasmus Research Institute of Management \\ (ERIM) Report ERS-2004-054-F\&A
}

\begin{abstract}
We derive an estimator for Black-Scholes-Merton implied volatility that, when compared to the familiar Corrado \& Miller [JBaF, 1996] estimator, has substantially higher approximation accuracy and extends over a wider region of moneyness.
\end{abstract}

Key words: implied volatility, options, approximation methods JEL classification: C13, C63, G13

\footnotetext{
*) Department of Finance, and Erasmus Research Institute of Management, Erasmus University Rotterdam, POB 1738, NL-3000 DR Rotterdam, The Netherlands.

Phone: +31.10.408-1290, facsimile: +31.10.408-9165. E-mail: hallerbach@few.eur.nl, homepage: http://www.few.eur.nl/few/people/hallerbach/.
} 


\section{An Improved Estimator For Black-Scholes-Merton Implied Volatility}

\section{Introduction}

Without doubt, the European call option pricing formulas developed by Black \& Scholes [1973] and Merton [1973] (henceforth BSM) mark a huge success in the history of financial modeling. Black [1975, p.64], however, was the first to observe volatility biases displayed by option market prices with respect to the BSM-formula. Out-of-the-money put options tend to be overpriced (giving rise to a high volatility implied by the BSM-model) and in-the-money put options tend to be underpriced (so the BSM-model implies a low volatility). ${ }^{1}$ This volatility "snear" or "skew" is quite common in equity derivatives markets, while foreign exchange derivatives exhibit volatility smiles in the sense that both in- and out-of-the-money options tend to have higher implied volatilities than at-the-money options.

The implied volatility smile effect is a well-documented empirical phenomenon. ${ }^{2}$ To uncover volatility smile patterns with respect to the BSM-model it is of great theoretical and practical importance to calculate volatilities implied by option market prices. Implied volatilities can be obtained either exactly by applying numerical methods ${ }^{3}$ or approximately by using approximation formulas. Two widely known and used examples of the latter category are the formulas derived by Brenner \& Subrahmanyam [1988] and Corrado \& Miller [1996b]. ${ }^{4,5}$ The Brenner \&

\footnotetext{
${ }^{1}$ From Put-Call parity it follows that European out-of-the-money calls (puts) exhibit the same price biases as in-the-money puts (calls). The seminal paper on implied volatilities is by Latané \& Rendleman [1976]. For extensive overviews, we refer to Mayhew [1995] and Corrado \& Miller [1996a].

${ }^{2}$ In his presidential address, Rubinstein [1994, pp.774ff] discusses the notable emergence of (stock index) volatility smiles after the stock market crash of October 1987.

${ }^{3}$ Notably the well-known Newton-Raphson procedure which has quadratic convergence, or Halley's method which is more stable and has cubic convergence. See Press et al. [1992] and http://mathworld.wolfram.com/HalleysMethod.html. Manaster \& Koehler [1982] present a starting value that guarantees convergence (except for the case where the option is exactly atthe-money-forward).

${ }^{4}$ A summary of Corrado \& Miller [1996b] appeared as Corrado \& Miller [1996c].
} 
Subrahmanyam [1988] formula only applies for at-the-money-forward options and is a special case of the more general Corrado \& Miller formula. In effect, the latter approximation formula is the best currently available.

In this paper we derive an alternative implied volatility estimator that compared to the conventional Corrado \& Miller [1996b] estimator exhibits substantially higher approximation accuracy and extends over a wider region of moneyness. Our formula is derived from a quadratic approximation of the option price around the at-the-money spanning point. Since first and second derivatives of an at-the-money option price with respect to the strike price are (approximate) functions of the at-the-money option price, we can next use the Brenner \& Subrahmanyam [1988] approximation to solve for the implied volatility.

The structure of the paper is as follows. In section 2 we summarize the Brenner \& Subrahmanyam [1988] and Corrado \& Miller [1996b] approximations. In section 3 we derive our approximation, both in raw (unadjusted) form and in tweaked form to further enhance approximation accuracy. We use the Corrado \& Miller [1996b] approximation as a benchmark. Section 4 further investigates approximation accuracy by means of root (weighted) mean squared approximation errors. Section 5 concludes and provides suggestions for future research.

\section{Implied volatility estimators}

The Black \& Scholes [1973] price of a European call option $C$ on a non-dividend paying stock $S$ with strike price $K$ and remaining maturity of $T$ years is given by:

$$
\begin{aligned}
& C=S \cdot N\left(d_{1}\right)-X \cdot N\left(d_{2}\right) \\
& \text { with } d_{1}=\frac{\ln (S / X)}{\sigma \sqrt{T}}+1 / 2 \sigma \sqrt{T} \quad \text { and } \quad d_{2}=d_{1}-\sigma \sqrt{T}
\end{aligned}
$$

where: $S=$ the current stock price,

\footnotetext{
${ }^{5}$ Other approximation formulas have been derived by Chance [1993] and Bharadia et al. [1996]. However, the former requires evaluation of the (inverse) cumulative normal distribution function and the latter is only fairly accurate for close at-the-money options.
} 
$X \equiv K e^{-r T}$ is the discounted strike price $K$, with riskfree interest rate $r^{6}$, $\sigma=$ the volatility of the underlying stock per annum,

and where $N(\cdot)$ is the cumulative standard normal distribution function.

The call option formula can be generalized as follows. ${ }^{7}$ When cash dividends are paid on the underlying stock, the current stock price $S$ is replaced by the current stock price less the present value of the dividends paid during the life of the option. For a European call option on a stock index paying a continuous dividend yield at rate $q$ per annum, the current stock price $S$ is replaced by $S \exp (-q T)$. For a European option on a foreign currency, $q$ is replaced by the foreign riskfree interest rate $r_{f}$. For a European commodity option, $q$ is replaced by $y$, the continuous compounded net convenience yield per annum. For a European futures option, finally, $q$ is replaced by the riskfree rate $r$ per annum and $S$ is replaced by the current futures price. When appropriate, these adjustments can be made throughout the rest of the paper.

For a call option that is at-the-money in the forward sense (henceforth denoted as ATM),

(2) $S=X$

eq.(1) reduces to:

$$
\begin{aligned}
C & =S \cdot N(1 / 2 \sigma \sqrt{T})-X \cdot N(-1 / 2 \sigma \sqrt{T}) \\
& =S[1-2 \cdot N(-1 / 2 \sigma \sqrt{T})]
\end{aligned}
$$

The Maclaurin series expansion of the cumulative normal distribution function is: ${ }^{8}$

$$
N(z)=1 / 2+\frac{1}{\sqrt{2 \pi}}\left[z+\mathrm{O}\left(z^{3}\right)\right]
$$

\footnotetext{
${ }^{6}$ A more general representation of the discount factor $\exp (-r T)$ is the current price of a riskfree zero-coupon bond with face value 1 , maturing at time $T$.

${ }^{7}$ See Hull [2003], e.g.

${ }^{8}$ See for example Stuart \& Ord [1987, p.184].
} 
Using the expansion (4) truncated after the first linear term in (3), Brenner \& Subrahmanyam [1988] derive the following approximation to the implied BSM volatility of an ATM call option:

$$
\sigma \sqrt{T} \approx \sqrt{2 \pi} \frac{C}{S} \quad \text { for } X=S
$$

In the same spirit, Corrado \& Miller [1996b] derive a more general formula, which extends the range of accuracy to a wider range of option moneyness. For nonATM options, the application of the linear normal distribution approximation (4) in (1) yields a quadratic equation in $\sigma \sqrt{T}$. After some manipulations, the relevant root of this equation is:

$$
\sigma \sqrt{T} \approx \sqrt{2 \pi}\left(\frac{C-1 / 2(S-X)}{S+X}\right)+\sqrt{2 \pi\left(\frac{C-1 / 2(S-X)}{S+X}\right)^{2}-\alpha\left(\frac{S-X}{S+X}\right)^{2}}
$$

with $\alpha=4$. For ATM options, (6) reduces to the Brenner \& Subrahmanyam [1988] approximation (5). Corrado \& Miller [1996b] next use the parameter $\alpha$ to minimize the concavity of (6) with respect to the stock price for $S=X$ (note that $\alpha$ is only relevant when $S \neq X$ ). Choosing $\alpha=2$, (6) reduces to their improved quadratic formula: ${ }^{9}$

$$
\sigma \sqrt{T} \approx \frac{\sqrt{2 \pi}}{S+X}\left(C-1 / 2(S-X)+\sqrt{(C-1 / 2(S-X))^{2}-\frac{(S-X)^{2}}{\pi}}\right)
$$

\section{An improved implied volatility estimator}

In this section, we derive an alternative implied volatility estimator. We start with a straddle, indicating the call $C$ and the put $P$ as explicit functions of the discounted strike price $X$ :

\footnotetext{
${ }^{9}$ Tweaking this formula further cannot improve approximation accuracy.
} 


$$
C(X)+P(X)=2 \cdot C(X)+X-S
$$

where the equality is implied by European Put-Call parity. ${ }^{10}$ A second order Taylor series approximation of the straddle around $X=S$ takes the form:

$$
C(X)+P(X) \approx 2 \cdot C(S)+(X-S)\left[C^{\prime}(S)+P^{\prime}(S)\right]+1 / 2(X-S)^{2}\left[C^{\prime \prime}(S)+P^{\prime \prime}(S)\right]
$$

where the primes indicate first and second order derivatives of the option prices with respect to the discounted strike price, evaluated at the argument between parentheses. Since $C^{\prime}(X)=-N\left(d_{2}\right)$ we have:

$$
C^{\prime}(S)=-N(-1 / 2 \sigma \sqrt{T})
$$

so we can express the ATM call price as:

$$
C(S)=S\left[1+2 \cdot C^{\prime}(S)\right]
$$

Combining this expression for the ATM call price with the Brenner \& Subrahmanyam [1988] approximation eq.(5) yields:

$$
\sigma \sqrt{T} \approx \sqrt{2 \pi}\left[1+2 \cdot C^{\prime}(S)\right]
$$

Since $C^{\prime \prime}(X)=\frac{N^{\prime}\left(d_{2}\right)}{X \sigma \sqrt{T}}$ we have:

$$
C^{\prime \prime}(S)=\frac{N^{\prime}(1 / 2 \sigma \sqrt{T})}{S \sigma \sqrt{T}}
$$

\footnotetext{
${ }^{10}$ Using a straddle only simplifies the derivation of the approximation. A second order approximation of a separate call option yields exactly the same implied volatility estimator.
} 
where $N^{\prime}(\cdot)$ is the standard normal density function. From (4) we have:

$$
N^{\prime}(1 / 2 \sigma \sqrt{T})=\frac{1}{\sqrt{2 \pi}}\left[1+\mathrm{O}\left(\sigma^{2}\right)\right] \approx \frac{1}{\sqrt{2 \pi}}
$$

Hence, using (12) and (14) in (13) gives:

$$
C^{\prime \prime}(S) \approx \frac{1}{2 \pi S\left[1+2 \cdot C^{\prime}(S)\right]}
$$

This simple ATM approximation holds very well for a wide range of volatilities.

Finally, from Put-Call parity we have:

$$
P^{\prime}(S)=C^{\prime}(S)+1 \quad \text { and } \quad P^{\prime \prime}(S)=C^{\prime \prime}(S)
$$

Plugging (8), (11), (15) and (16) in (9) gives:

$$
2 \cdot C(X)+X-S \approx(S+X)\left[1+2 \cdot C^{\prime}(S)\right]+\frac{(X-S)^{2}}{2 \pi S\left[1+2 \cdot C^{\prime}(S)\right]}
$$

Multiplying both sides with $1+2 \cdot C^{\prime}(S)$ yields:

$$
(S+X)\left[1+2 \cdot C^{\prime}(S)\right]^{2}-(2 \cdot C(X)+X-S)\left[1+2 \cdot C^{\prime}(S)\right]+\frac{(X-S)^{2}}{2 \pi S} \approx 0
$$

Treating this expression as exact, $(18)$ is a quadratic form in $1+2 \cdot C^{\prime}(S)$. Its largest root is:

$$
1+2 \cdot C^{\prime}(S)=\frac{2 C(X)+X-S+\sqrt{(2 C(X)+X-S)^{2}-2(S+X) \frac{(X-S)^{2}}{\pi S}}}{2(S+X)}
$$


Only the largest root is consistent with (11) when $S=X$ (the smallest root gives zero in that case). Using (12), we get, with $C=C(X)$ :

$$
\sigma \sqrt{T}=\frac{\sqrt{2 \pi}}{2(S+X)}\left[2 C+X-S+\sqrt{(2 C+X-S)^{2}-2(S+X) \frac{(X-S)^{2}}{\pi S}}\right]
$$

Note that for ATM options, (20) reduces to the Brenner \& Subrahmanyam [1988] approximation (5). Rewriting (20) as:

$$
\sigma \sqrt{T}=\sqrt{2 \pi} \frac{C+1 / 2(X-S)}{S+X}+\sqrt{2 \pi\left(\frac{C+1 / 2(X-S)}{S+X}\right)^{2}-\frac{(X-S)^{2}}{S(S+X)}}
$$

and comparing it to the unadjusted formula of Corrado \& Miller [1996b] in eq.(6) with $\alpha=4$, their last term under the square root is $4\left(\frac{S-X}{S+X}\right)^{2}$ whereas in our eq.(21) this term can be expressed as $4\left(\frac{S-X}{S+X}\right)^{2}\left[\frac{S+X}{4 S}\right]$, thus incorporating the extra term between square brackets.

We first compare the accuracy of eq.(20) with the unadjusted Corrado \& Miller [1996b] formula eq.(6), where $\alpha=4$. Since the BSM option is linearly homogeneous in the underlying and the (discounted) strike price, we normalize with respect to the current stock price. ${ }^{11}$ The discounted strike divided by the current stock price, $M \equiv X / S$, indicates the moneyness of the option.

In Figure 1, we plot implied volatilities $(\sigma \sqrt{T})$ for moneyness ranging from $80 \%$ to $120 \%$. This range covers the degree of moneyness encountered in practice very well. We consider volatilities $\sigma \sqrt{T}$ over the range from $3 \%$ to $30 \%$. A volatility of $30 \%(50 \%)$ per annum, for example, roughly translates into a volatility of $3 \%$ over one month (two weeks). A volatility of just over $25 \%$ per annum means a volatility of

\footnotetext{
${ }^{11}$ This linear homogeneity was first noticed by Merton [1973] as a special characteristic. It was generalized by Hoogland \& Neumann [2001a,b] who recognized it as a fundamental property and even termed it "the relativity principle of finance" (p.6).
} 
Figure 1: Accuracy of the unadjusted implied volatility estimators.

Panel A covers the implied volatilities $\sigma \sqrt{T}=0.15,0.20,0.25,0.30$ and panel B shows $\sigma \sqrt{T}=0.03,0.05,0.08,0.10$, according to unadjusted estimates of Corrado \& Miller's [1996b] formula eq.(6) and our eq.(20). The bold (flatter top) curves represent our estimates.

Panel A: $\sigma \sqrt{T}=0.15,0.20,0.25,0.30$

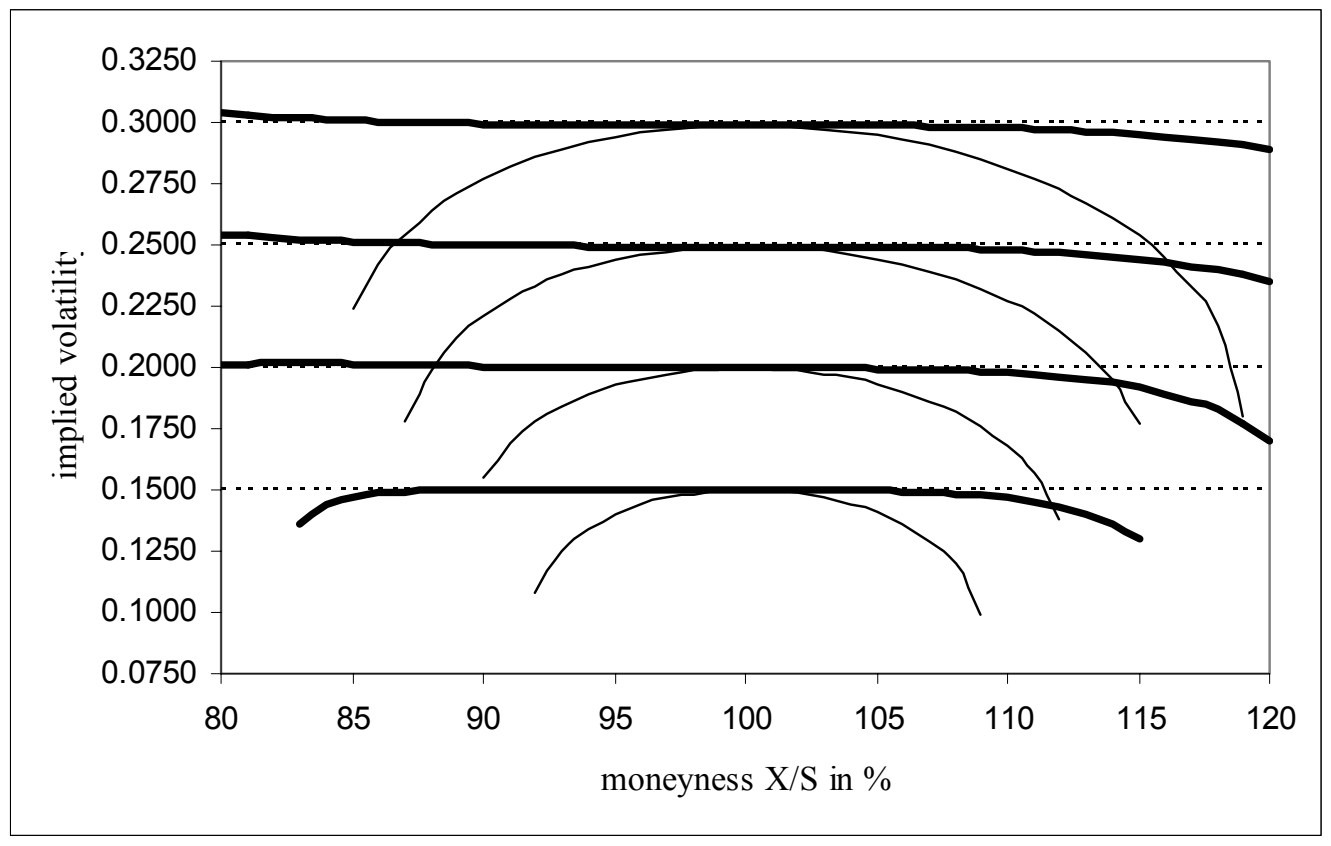

Panel B: $\sigma \sqrt{T}=0.03,0.05,0.08,0.10$

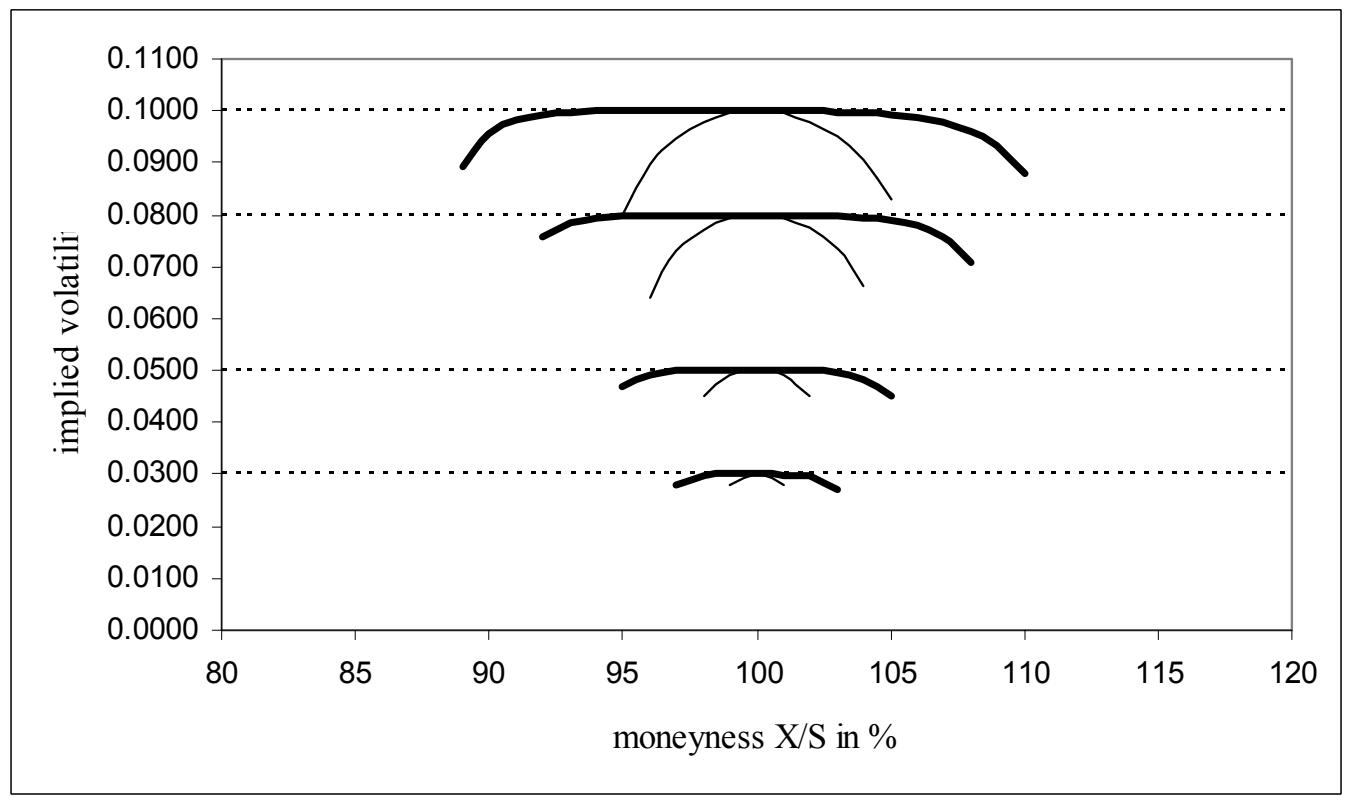


$8 \%$ over one month. In panel A, implied volatilities $\sigma \sqrt{T}=0.15,0.20,0.25,0.30$ are covered whereas panel B depicts $\sigma \sqrt{T}=0.03,0.05,0.08,0.10$. When implied volatilities are not shown in the graph, the corresponding formula yields no real solution. ${ }^{12}$ The fat top curves, fairly straight, indicate our unadjusted approximation according to eq.(20) whereas the unadjusted Corrado \& Miller [1996b] formula eq.(6) yields the more concave curves. Even without further adjustment, approximation accuracy of (20) is already very good. It also yields estimates over a wider range of moneyness. The higher the volatility, the better the approximation accuracy of (20); therefore, we do not show results for $\sigma \sqrt{T}>0.30$.

Next we tweak our approximant (20) to further improve approximation accuracy. We start rewriting it as:

$$
\sigma \sqrt{T}=\frac{\sqrt{2 \pi}}{2(S+X)}\left[2 C+X-S+\sqrt{(2 C+X-S)^{2}-\gamma(S+X) \frac{(X-S)^{2}}{\pi S}}\right]
$$

where $\gamma=2$. By adjusting the tweaking parameter $\gamma$ we can change the curvature of (22) without affecting the approximation accuracy for ATM options. Evaluating the approximation accuracy for a range of $\sigma \sqrt{T}=0.03, \ldots, 0.30$ we find that a somewhat lower value of $\gamma=1.85$ performs best. However, the implied volatility estimates show a tendency to overshoot for low moneyness $M$ and undershoot for high $M$. This is also observed in Figure 1 Panel A for the unadjusted approximation in the higher implied volatility range. We therefore also include a moneyness correction in the tweaking factor to further enhance approximation accuracy: ${ }^{13}$

$$
\gamma=1.85 \sqrt{\frac{S}{X}}
$$

\footnotetext{
${ }^{12}$ The discriminant of eq.(18) becomes negative and hence its roots are imaginary.

${ }^{13} \mathrm{We}$ admit that this is more art than science, but our only goal is to obtain accurate implied volatility estimates for a wide range of moneyness.
} 
For $M=80 \%(120 \%)$ we have $\sqrt{S / X}=0.894(1.095)$, so depending on the degree of moneyness we have a tilt of $-10 \%$ to $+10 \%$. Hence, our tweaked formula finally becomes:

$$
\sigma \sqrt{T}=\frac{\sqrt{2 \pi}}{2(S+X)}\left[2 C+X-S+\sqrt{(2 C+X-S)^{2}-1.85 \frac{(S+X)(X-S)^{2}}{\pi \sqrt{X S}}}\right]
$$

Figure 2 compares Corrado \& Miller's [1996b] improved (adjusted) quadratic formula eq.(7) with our tweaked approximant eq.(24). We again plot implied volatilities against the range of moneyness. Panel A again covers implied volatilities $\sigma \sqrt{T}=0.15,0.20,0.25,0.30$ and panel B shows the estimates for the selection $\sigma \sqrt{T}=0.03,0.05,0.08,0.10$. The almost straight fat top curves indicate our tweaked estimator eq.(24). The improved Corrado \& Miller [1996b] formula eq.(7) does a fair job, but it yields more concave curves and extends over a more narrow range of moneyness. Our approximation is outstanding over a wide range of moneyness both in absolute sense and when compared to the Corrado \& Miller [1996b] formula. This not only applies to low implied volatilities $\sigma \sqrt{T}$ which are relevant for short maturity options, but also to higher implied volatilities which are relevant for longer maturity options. Especially for the latter options the approximation accuracy in the lower moneyness region is relevant. After all, for longer maturity options which are at-themoney in the conventional sense (i.e. $K=S$ ), we expect that $X<<S$ and hence $M<<100 \%$. 
Figure 2: Accuracy of the adjusted implied volatility estimators.

Panel A covers the implied volatilities $\sigma \sqrt{T}=0.15,0.20,0.25,0.30$ and panel B depicts $\sigma \sqrt{T}=0.03,0.05,0.08,0.10$, according to adjusted estimates of Corrado \& Miller's [1996b] formula eq.(7) and our tweaked approximant eq.(24). The bold (flatter top) curves represent our estimates.

Panel A: $\sigma \sqrt{T}=0.15,0.20,0.25,0.30$

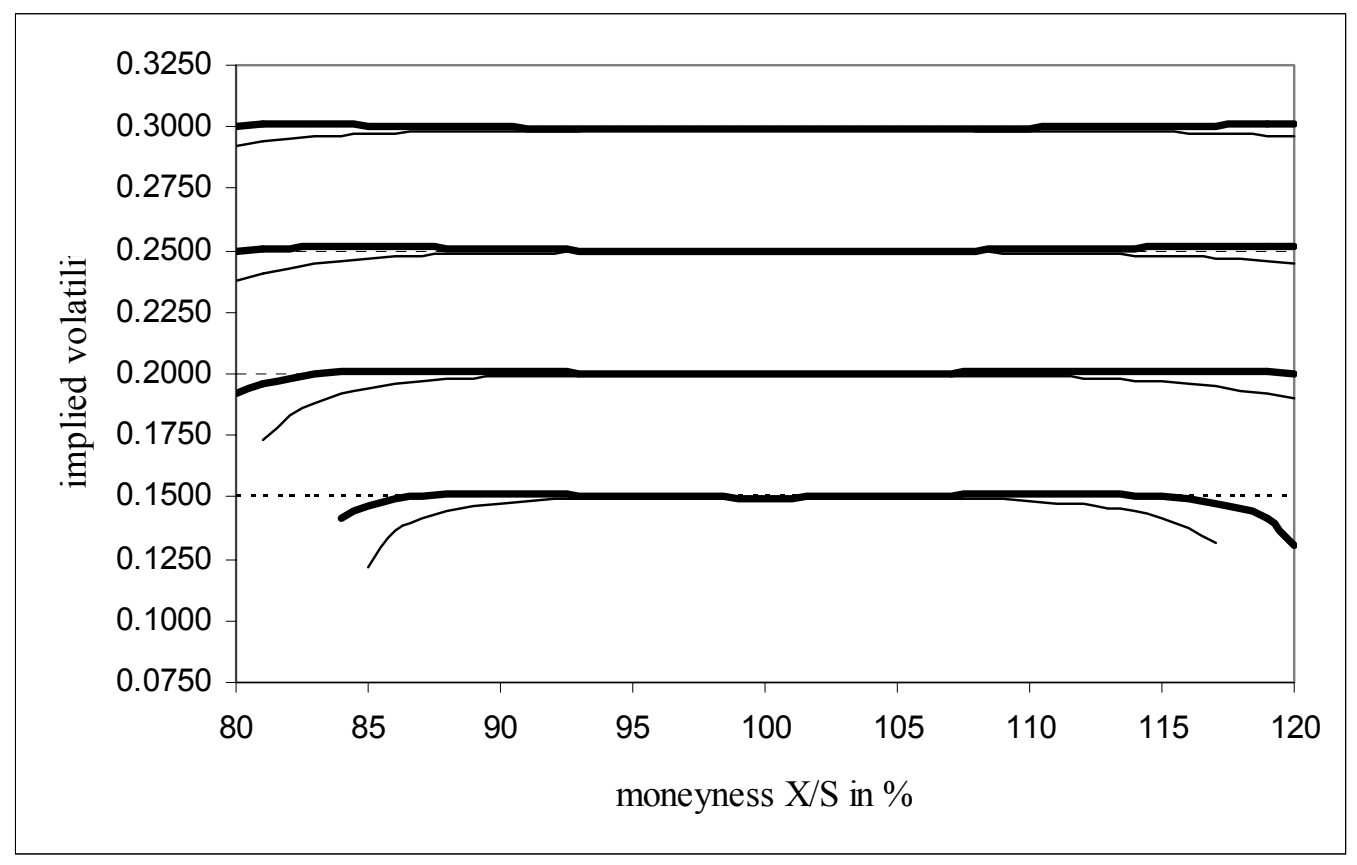

Panel B: $\sigma \sqrt{T}=0.03,0.05,0.08,0.10$

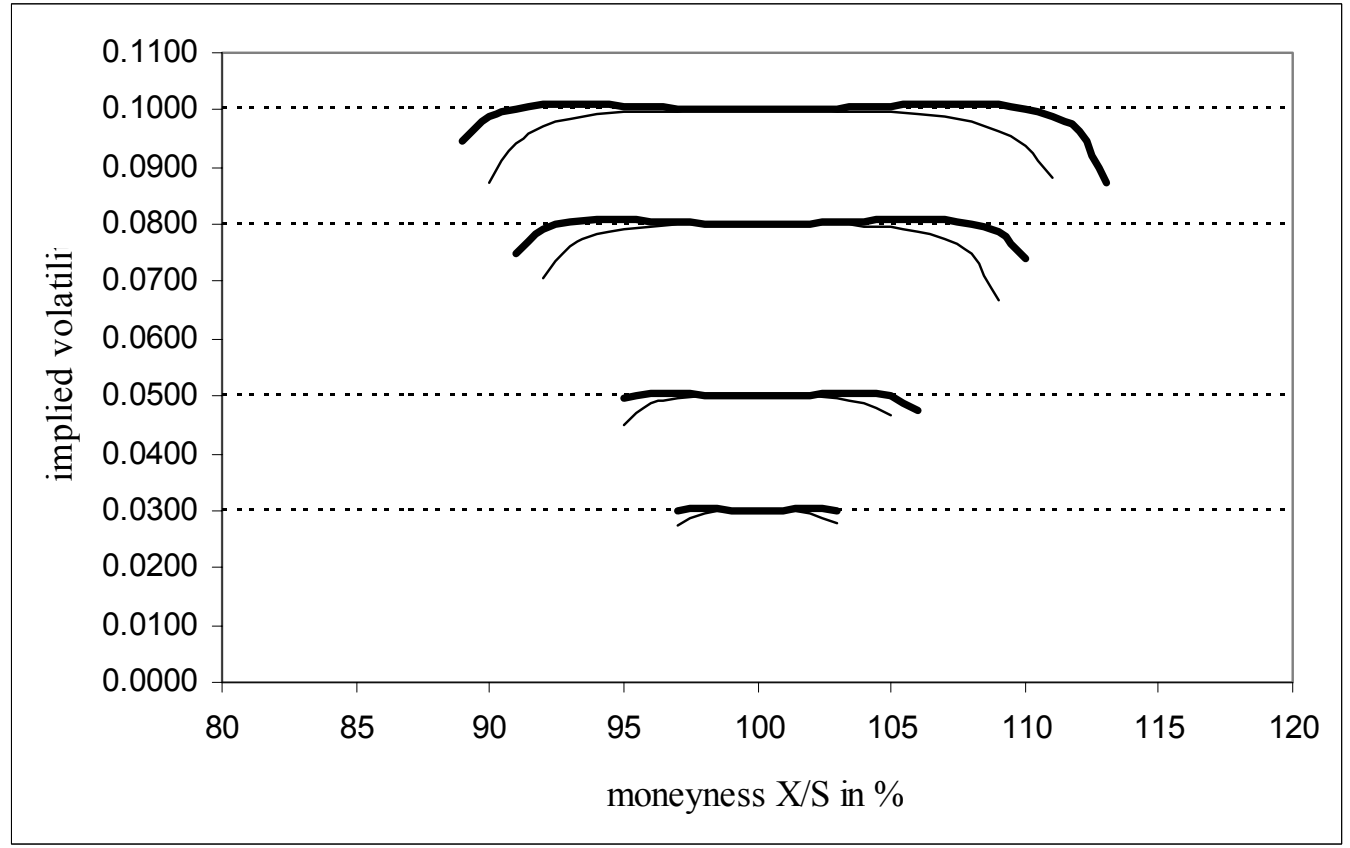




\section{A closer look at approximation accuracy}

To gain further insight into the approximation accuracy, we compute root mean squared approximation errors. We consider moneyness $M=X / S$ over the maximum range of $80 \%$ to $120 \%$ in steps of $1 \%$. Since the Corrado \& Miller [1996b] approximation is our benchmark, we only consider the range of moneyness $\{M *\}$ for which their formula yields an implied volatility estimate. The number of percentage levels of moneyness considered is the cardinality of $\left\{M^{*}\right\}$, indicated as $|M *|$.

The root mean squared error (RMSE) of an approximation is computed as:

$$
\operatorname{RMSE}\left(\sigma \sqrt{T} ; M^{*}\right)=\sqrt{\frac{1}{\left|M^{*}\right|} \sum_{i \in M^{*}}(\hat{\sigma} \sqrt{T}-\sigma \sqrt{T})^{2}}
$$

where $\hat{\sigma} \sqrt{T}$ is the implied volatility from the corresponding approximation. This is the unweighted RMSE. Since vega is highest for ATM options and decreases when the option moves further in- or out-of-the-money, it makes sense to weigh the squared approximation errors with vega. ${ }^{14}$ After all, the more an option is in- or out-of-themoney, the lower its sensitivity to changes in volatility and hence the less important the approximation error. The vega of a European call, normalized to the current stock price, $C / S$, is:

$$
\frac{\partial C / S}{\partial \sigma \sqrt{T}}=N^{\prime}\left(d_{1}\right)
$$

where $d_{1}$ is as defined in (1). Hence, for each level $i$ of moneyness in $\left\{M^{*}\right\}$ we define the weight:

$$
w_{i}=\frac{N^{\prime}\left(d_{1}\right)_{i}}{\sum_{j \in M^{*}} N^{\prime}\left(d_{1}\right)_{j}} \quad \forall i \in M^{*}
$$

\footnotetext{
${ }^{14}$ A weighting scheme on the basis of the options' vegas was first applied by Latané \& Rendleman [1976].
} 
where $N^{\prime}\left(d_{1}\right)_{i}$ indicates $N^{\prime}\left(d_{1}\right)$ evaluated at moneyness level $i$. We have normalized the weights to sum to unity for each $\left\{M^{*}\right\}$. The root weighted-mean squared error (RWMSE) is then computed as:

$$
\operatorname{RWMSE}\left(\sigma \sqrt{T} ; M^{*}\right)=\sqrt{\sum_{i \in M^{*}} w_{i}(\hat{\sigma} \sqrt{T}-\sigma \sqrt{T})^{2}}
$$

Table 1: Approximation accuracy, as measured by RMSE (unweighted, see eq.(25)) and RWMSE (vega-weighted, see eq.(28)). Comparison is between the improved Corrado \& Miller [1996b] (C\&M) formula eq.(7) and our tweaked approximation eq.(24). The R(W)MSEs are expressed in percentage terms. Below the R(W)MSE of our approximation is the R(W)MSE of our approximation expressed as a percentage of the corresponding C\&M's $\mathrm{R}(\mathrm{W}) \mathrm{MSE}$.

\begin{tabular}{|c|c|c|c|c|c|}
\hline \multirow[b]{2}{*}{$\sigma \sqrt{T}$} & \multirow{2}{*}{$\begin{array}{c}\text { moneyness } \\
M \text { in } \%\end{array}$} & \multicolumn{2}{|c|}{ RMSE } & \multicolumn{2}{|c|}{ RWMSE } \\
\hline & & C\&M & our eq.(24) & C\&M & our eq.(24) \\
\hline \multirow[t]{2}{*}{$3 \%$} & $97-103$ & 0.1368 & 0.0189 & 0.1179 & 0.0188 \\
\hline & & & $14 \%$ & & $16 \%$ \\
\hline \multirow[t]{2}{*}{$5 \%$} & $95-105$ & 0.1936 & 0.0341 & 0.1654 & 0.0331 \\
\hline & & & $18 \%$ & & $20 \%$ \\
\hline \multirow[t]{2}{*}{$8 \%$} & $92-109$ & 0.4179 & 0.0620 & 0.3537 & 0.0579 \\
\hline & & & $15 \%$ & & $16 \%$ \\
\hline \multirow[t]{2}{*}{$10 \%$} & $90-111$ & 0.4304 & 0.0700 & 0.3649 & 0.0661 \\
\hline & & & $16 \%$ & & $18 \%$ \\
\hline \multirow[t]{2}{*}{$15 \%$} & $85-117$ & 0.7208 & 0.1089 & 0.6005 & 0.0983 \\
\hline & & & $15 \%$ & & $16 \%$ \\
\hline \multirow[t]{2}{*}{$20 \%$} & $81-120$ & 0.6247 & 0.1120 & 0.5178 & 0.1007 \\
\hline & & & $18 \%$ & & $19 \%$ \\
\hline \multirow[t]{2}{*}{$25 \%$} & $80-120$ & 0.3408 & 0.0786 & 0.3006 & 0.0765 \\
\hline & & & $23 \%$ & & $25 \%$ \\
\hline \multirow[t]{2}{*}{$30 \%$} & $80-120$ & 0.2618 & 0.0712 & 0.2450 & 0.0719 \\
\hline & & & $27 \%$ & & $29 \%$ \\
\hline
\end{tabular}

Table 1 shows the weighted and unweighted RMSEs. Almost without exception, RWMSE is lower than RMSE: although approximation accuracy decreases when moving to lower and higher levels of moneyness, also the corresponding vega-weight 
decreases. Also, R(W)MSEs seem to be highest in the $15 \%$ to $20 \%$ volatility range. Corrado \& Miller's [1996b] unweighted RMSE ranges from 14 to 72 basis points (bps), as compared to only 2 to $11 \mathrm{bps}$ for our approximant (in relative terms this is 14 to $27 \%$ ). Switching to the weighted case, the RWMSE of our approximation is 16 to 29\% of Corrado \& Miller's [1996b] RWMSE, ranging from 2 to $10 \mathrm{bps}$. So in all cases where Corrado \& Miller's [1996b] approximant yields an implied volatility estimate, our estimator is expected to reduce approximation error with at least $70 \%$.

Since the range of moneyness $M^{*}$ is truncated at the points where the Corrado \& Miller [1996b] estimator fails to deliver an implied volatility estimate, we also evaluated the approximation accuracy of our estimator over its own relevant range of moneyness. Table 2 shows the details. Comparing with Table 1, the RMSE and RWMSE is substantially lower than for the Corrado \& Miller [1996b] estimator for all levels of volatility considered. For the unweighted case, approximation error ranges from 2 to $40 \mathrm{bps}$, and for the weighted case from 2 to $32 \mathrm{bps}$. This signifies an important improvement over the Corrado \& Miller [1996b] estimator.

Table 2: Approximation accuracy of our tweaked approximation eq.(24), as measured by RMSE (unweighted, see eq.(25)) and RWMSE (vega-weighted, see eq.(28)), over the whole relevant range of moneyness. The R(W)MSEs are expressed in percentage terms.

\begin{tabular}{rcrr}
\hline \multicolumn{3}{c}{ moneyness } & \\
$\sigma \sqrt{T}$ & $M$ in $\%$ & RMSE & RWMSE \\
\hline $3 \%$ & $97-103$ & 0.0189 & 0.0188 \\
$5 \%$ & $95-106$ & 0.0797 & 0.0668 \\
$8 \%$ & $91-110$ & 0.1809 & 0.1469 \\
$10 \%$ & $89-113$ & 0.2936 & 0.2366 \\
$15 \%$ & $84-120$ & 0.3957 & 0.3226 \\
$20 \%$ & $80-120$ & 0.1717 & 0.1406 \\
$25 \%$ & $80-120$ & 0.0786 & 0.0765 \\
$30 \%$ & $80-120$ & 0.0712 & 0.0719 \\
\hline
\end{tabular}




\section{Summary and conclusions}

In this paper, we derived an alternative estimator for implied volatility in the standard Black-Scholes-Merton framework. This estimator provides accurate implied volatility estimates over a wide range of moneyness and significantly improves on the familiar Corrado \& Miller [1996b] approximation formula. Especially in spread sheet applications where closed-form approximants are favored, the higher approximation accuracy paired with the wider range of moneyness are very welcome features of our proposed estimator. Whereas the Corrado \& Miller [1996b] formula signified an important step forward in closed-form implied volatility estimations, our results imply that further improvements can be achieved. We therefore would like to encourage further research in this area. 


\section{References}

Bharadia, M.A.J., N. Christophides \& G.R. Salkin, 1996, “A Quadratic Method for the Calculation of Implied Volatility Using the Garman-Kohlhagen Model", Financial Analysts Journal March/April, pp.61-64

Black, F., 1975, "Fact and Fantasy in the Use of Options", Financial Analysts Journal 31 , pp.36-41, 61-72

Black, F. \& M. Scholes, 1973, "The Pricing of Options and Corporate Liabilities", The Journal of Political Economy 81/3, pp. 637-659

Brenner, M. \& M.G. Subrahmanyam, 1988, "A Simple Formula to Compute the Implied Standard Deviation”, Financial Analysts Journal, Sept/Oct, pp.80-83

Chance, D., 1993, "Leap Into The Unknown”, RISK 6/5, May, pp.60-66

Corrado, C.J. \& T.W. Miller, 1996a, "Efficient Option-Implied Volatility Estimators", The Journal of Futures Markets 16/3, pp. 247-272

Corrado, C.J. \& T.W. Miller, 1996b, "A Note On A Simple, Accurate Formula to Compute Implied Standard Deviations”, Journal of Banking \& Finance 20, pp.595-603

Corrado, C.J. \& T.W. Miller, 1996c, "Volatility Without Tears", RISK 9/7, July, pp. $49-52$

Hoogland, J.K. \& C.D.D. Neumann, 2001a, "Local Scale Invariance and Contingent Claim Pricing", International Journal of Theoretical and Applied Finance 4/1, pp.1-21

Hoogland, J.K. \& C.D.D. Neumann, 2001b, "Local Scale Invariance and Contingent Claim Pricing II: Path-Dependent Contingent Claims", International Journal of Theoretical and Applied Finance 4/1, pp.23-43

Hull, J.C., 2003, “Options, Futures and Other Derivatives”, Prentice-Hall, Englewood Cliffs NJ

Latané, H. \& R. Rendleman, 1976, "Standard Deviations of Stock Price Ratios Implied in Option Prices", The Journal of Finance 31, May, pp.369-381

Manaster, S. \& G. Koehler, 1982, "The Calculation of Implied Variances from the Black-Scholes Model: A Note", The Journal of Finance 37, pp.227-230

Mayhew, S., 1995, "Implied Volatility”, Financial Analysts Journal, July/August, pp. $8-20$

Merton, R.C., 1973, "Theory of Rational Option Pricing”, Bell Journal of Economics and Management Science 4/1, pp.141-183

Press, W.H., B.P. Flannery, S.A. Teukolsky \& W.T. Vetterling, 1992, "Numerical Recipes in C: The Art of Scientific Computing”, Cambridge University Press, Cambridge MA

Rubinstein, M., 1994, "Implied Binomial Trees”, The Journal of Finance 69/3, July, pp.771-818

Stuart, A. \& J.K. Ord, 1987, "Kendall's Advanced Theory of Statistics, Volume 1", Oxford University Press, New York NY 


\section{Publications in the Report Series Research* in Management}

\section{ERIM Research Program: "Finance and Accounting"}

2004

Corporate Finance In Europe Confronting Theory With Practice

Dirk Brounen, Abe de Jong and Kees Koedijk

ERS-2004-002-F\&A

http://hdl.handle.net/1765/1111

Downside Risk And Asset Pricing

Thierry Post and Pim van Vliet

ERS-2004-018-F\&A

http://hdl.handle.net/1765/1424

An Alternative Decomposition Of The Fisher Index

Winfried G. Hallerbach

ERS-2004-022-F\&A

http://hdl.handle.net/1765/1220

A Gmm Test For Ssd Efficiency

Thierry Post And Philippe Versijp

ERS-2004-024-0F\&A

http://hdl.handle.net/1765/1426

Purchasing Power Parity and the Euro Area

Kees G. Koedijk, Ben Tims and Mathijs A. van Dijk

ERS-2004-025-F\&A

http://hdl.handle.net/1765/1442

The effects of systemic crises when investors can be crisis ignorant

Erik Kole, Kees Koedijk \& Marno Verbeek

ERS-2004-027-F\&A

http://hdl.handle.net/1765/1270

Shareholders' Voting at General Meetings: Evidence from the Netherlands

Abe De Jong, Gerard Mertens And Peter Roosenboom

ERS-2004-039-F\&A

http://hdl.handle.net/1765/1332

Do banks influence the capital structure choices of firms?

Petra Daniševská, Abe de Jong \& Marno Verbeek

ERS-2004-040-F\&A

http://hdl.handle.net/1765/1333

* A complete overview of the ERIM Report Series Research in Management: https://ep.eur.nl/handle/1765/1

ERIM Research Programs:

LIS Business Processes, Logistics and Information Systems

ORG Organizing for Performance

MKT Marketing

F\&A Finance and Accounting

STR Strategy and Entrepreneurship 
The Eco-Efficiency Premium Puzzle

Jeroen Derwall, Nadja Günster, Rob Bauer and Kees Koedijk

ERS-2004-043-F\&A

http://hdl.handle.net/1765/1296

Conditional Downside Risk and the CAPM

Thierry Post And Pim Van Vliet

ERS-2004-048-F\&A

http://hdl.handle.net/1765/1425

It Takes Two To Tango: An Empirical Tale Of Distressed Firms And Assisting Banks

Oscar Couwenberg and Abe de Jong

ERS-2004-049-F\&A

http://hdl.handle.net/1765/1444

An Improved Estimator For Black-Scholes-Merton Implied Volatility

Winfried G. Hallerbach

ERS-2004-054-F\&A 